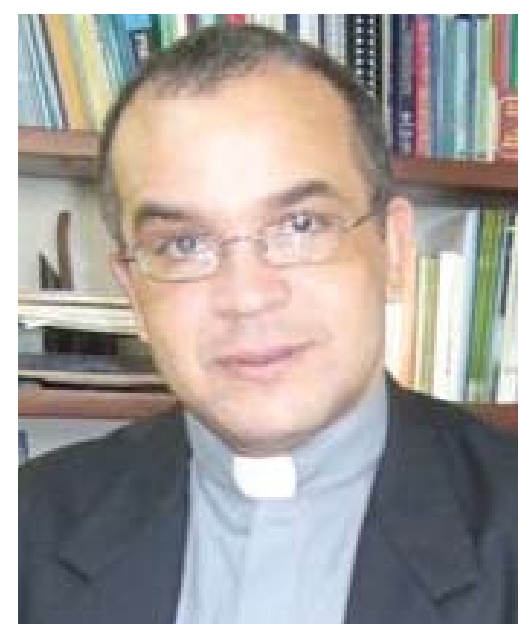

Este artículo ofrece una visión general de lo social como eje transversal de la Encíclica Mater et Magistra, lo cual permite un acercamiento al currículo de la Pontifica Universidad Católica Madre y Maestra. Se pregunta si el currículo de la PUCMM fomenta en sus estudiantes y docentes la conciencia social, como una actitud que lleva a la persona humana a actuar buscando siempre el bien del otro, su crecimiento y promoción. Es, sin duda, algo arriesgado y a la vez desafiante, pues como universidad le corresponde su rol de profesionalizar. Sin embargo, su misión como universidad católica la obliga a no olvidar que la profesionalización serátal, si promueve el crecimiento en el ser humano y si los estudiantes, al terminar sus estudios, evidencian una clara conciencia social.

\title{
ECOS DESDELAS FACULTADES
}

\section{EL CURRÍCULO DE LA PUCMM Y LA EDUCACIÓN DE LA CONCIENCIA SOCIAL A LA LUZ DE LA ENCÍCLICA MATER ET MAGISTRA}

\section{P. Ramón Alfredo de la Cruz*}

La Pontificia Universidad Católica Madre y Maestra surge inspirada por la Encíclica Mater et Magistra de su Santidad Juan XXIII, quien en 1961, observando el creciente desarrollo industrial y social de la época, presenta ante el mundo un análisis social de dicho desarrollo. El papa fundamenta su análisis retomando la temática social, planteada setenta años atrás (1891) por el papaLeónXIII ensuencíclicaRerumNovarum, así como el aporte de la doctrina social de la Iglesia hasta ese momento.

Uno de los objetivos principales de la Mater et Magistra es hacer un llamado a la conciencia universal, para que toda la humanidad se esfuerce en la formación de una nueva sociedad, la cual esté basada en el bien común y en la preocupación por el desarrollo de la sociedad humana. Con ella, la Iglesia reafirma su interés en la promoción del bien común y del desarrollo de los pueblos.

Su santidad Juan XXIII hace un llamado a la integración de todos los sectores sociales, con el fin de promover, con toda la capacidad, el desarrollo social como una oportunidad para poder vencer los obstáculos de la pobreza. De este modo, la Encíclica se hace eco de la preocupación social, desafiada por el rápido crecimiento del mundo industrial, desligando de dicho proceso a los hombres y mujeres del campo, el cual, a su vez, se convertía en un sector deprimido (123)'. La consecuencia de tal desarrollo no se dejó esperar: una gran ola emigratoria del campo a la ciudad caracterizó las décadas de los sesenta y setenta del siglo XX, provocando una disminución de la población rural y un aumento desproporcionado y antihumano de las grandes urbes.

Acogiendo el llamado de la Mater et Magistra de promover el desarrollo social de los pueblos, la Conferencia del Episcopado Dominicano funda la Universidad Católica Madre y Maestra. Por medio de la docencia, la investigación y la extensión, la Institución se compromete a promover en el pueblo dominicano la nueva conciencia social e impulsar su desarrollo social, económico y cultural. Es así que la Universidad, desde su comienzo, ofrece aquellas carreras que se consideran prioritarias para el desarrollo del paísy, enunprocesocontinuo de actualización, ofrece programas y actividades que van directamente a presentar soluciones a los problemas del presente.

\section{Concepto de Currículo}

Entendemos como currículo todos aquellos elementos que contienen un fin educativo, ya sea implícito o explícito. Por lo tanto, todas las actividades académicas quedan incluidas en un concepto amplio de currículo (Sevillano, 2004). Si bien es cierto que el currículo encuentra su mayor concreción en los programas de las asignaturas, éste se quedaría estrecho si solo permaneciera a nivel de los mismos. En consecuencia, es necesario complementarlo a través de otras actividades que dinamicen y promueven la vida académica (Flórez Ochoa, 2005). El currículo no es incorporado a la institución académica, él debe ser toda la academia. La universidad es lo que sea su currículo.

* Sacerdote diocesano. Doctor en Teología (Pedagogía Religiosa) por la Universidad Rheinische Friedrich-Wilhelm de Bonn, Alemania. Director del Departamento de Educación y profesor a tiempo completo de la PUCMM.

' Los números entre paréntesis indican los párrafos correspondientes en la Encíclica, numerados de la misma forma en todas las ediciones completas. 


\section{La conciencia social}

Al hablar de conciencia, siempre se hace referencia a un conocimiento que implica un saber distinguir entre dos o más realidades. Tener conciencia de algo es conocer lo que ese algo es y poder vivenciarlo en su ser (incorporarlo al yo). Es decir, la conciencia implica tener una vivencia de algo y poder, a la vez, interiorizarlo y exteriorizarlo de tal manera, que la realidad conocida o vivenciada no estén separadas (Brugger, 2003).

La conciencia social es la conformidad entre el bien deseado y el bien realizado. Es una actitud que lleva a la persona humana a actuar siempre buscando el bien del otro, su crecimiento, la promoción del otro. En consecuencia, en la búsqueda del bien siempre se trata de alcanzar el progreso social.

La conciencia social siempre indica una actitud volcada a una acción-reflexión y viceversa. Dada esta dimensión, se hace difícil hablar de la educación de una conciencia social, ya que ella es un valor y, como tal, más que enseñada por medio a una cátedra, ella debe ser vivida, pues los valores solo se aprenden por medio de la experiencia compartida con personas concretas en un tiempo y espacio definido.

La palabra conciencia aparece diez veces en la Mater et Magistra y en ninguna de las menciones se señala como conciencia social. De ahí que tenemos que verla en relación al llamado a la conciencia que se hace en la misma y su abstracción se realiza mediante el fin que la conciencia busca, lo social.

Por otra parte, es ante los problemas acuciantes de la sociedad de entonces que la Encíclica hace el llamado a despertar la conciencia frente a las diferentes situaciones que afectan a la población, de manera muy especial a los más pobres y marginados de la sociedad (158). Esto se refleja mayormente en los hombres y mujeres del campo, a quienes el Papa invita a tener conciencia clara de la nobleza de su profesión, pues ellos trabajan "en el templo majestuoso de la Creación" (144). Aquí el documento incursiona en una teología de la creación que exalta el trabajo de la tierra.

Ante estellamado, el Papareconoce los esfuerzos que se estaban realizando a favor de la justicia social: "Sabemos perfectamente cómo en estos últimos años ha ido profundizándose en muchos hombres la conciencia de la obligación que tienen de ayudar a los países pobres, que se hallan todavía en situación de subdesarrollo, a fin de lograr que en éstos se faciliten los avances del desarrollo económico y del progreso social" (164).

\section{PUCMM, currículo y conciencia social}

Visto el eje transversal de lo social en la Encíclica, queremos acercarnos a la hoy Pontifica Universidad Católica Madre y Maestra y preguntarnos si el currículo de la misma fomenta en sus estudiantes y docentes la conciencia social, como una actitud que lleva a la persona humana a actuar siempre buscando el bien del otro, su crecimiento y promoción. Esto es, sin duda, algo arriesgado y a la vez desafiante, pues como universidad le corresponde su rol de profesionalizar. Sin embargo, su misión como universidad católica le obliga a no olvidar que la profesionalización será tal, si promueve el crecimiento en el ser humano y si los estudiantes, al terminar sus estudios, evidencian una clara conciencia social. La Mater et Magistra insiste incluso en este sentido:

Como ya hemos recordado, los hombres de nuestra época han profundizado y extendido la investigación de las leyes de la naturaleza; han creado instrumentos nuevos para someter a su dominio las energías naturales; han producido y siguen produciendo obras gigantescas y espectaculares. Sin embargo,

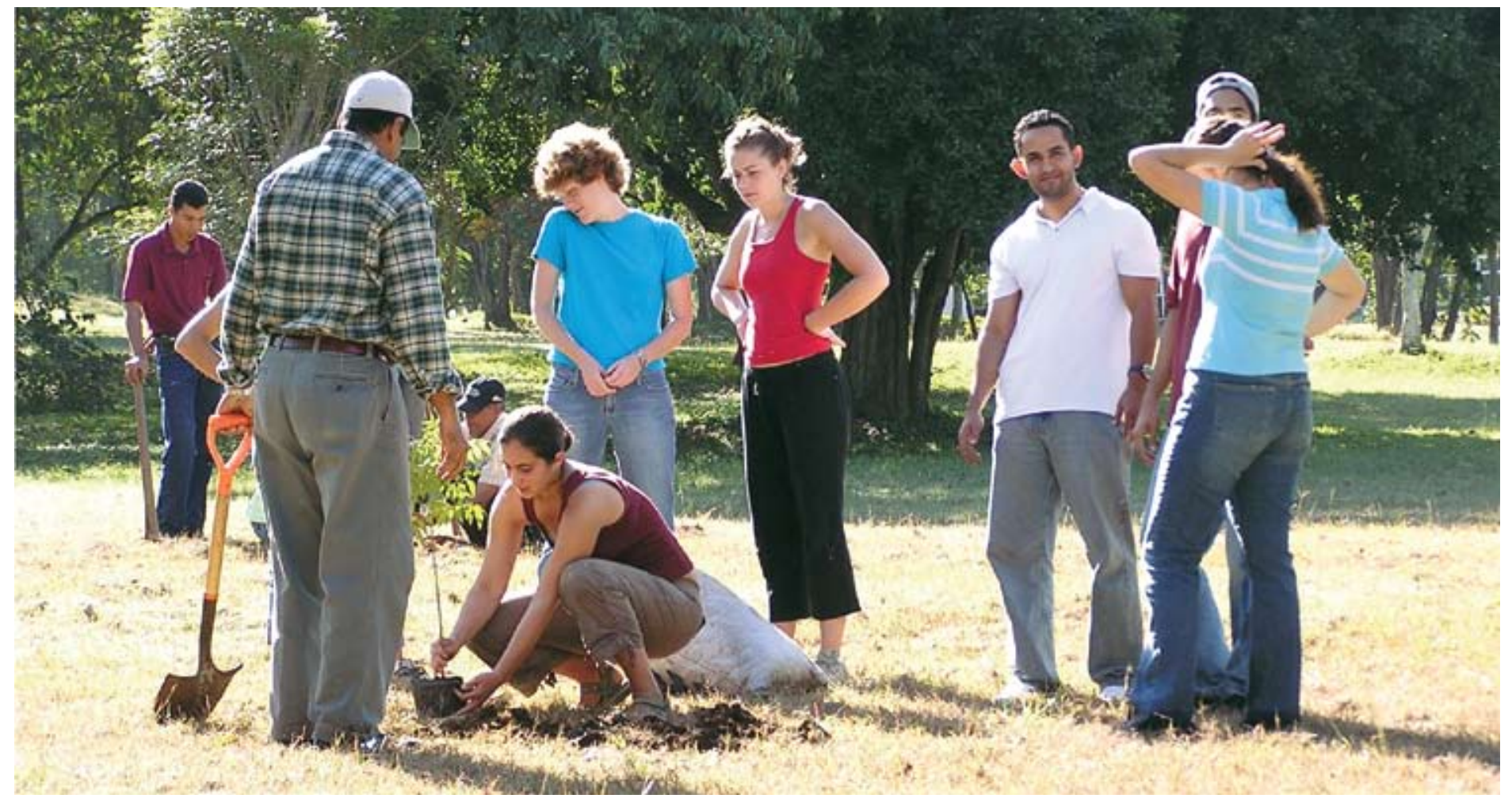


mientras se empeñan en dominar y transformar el mundo exterior, corren el peligro de incurrir por negligencia en el olvido de sí mismos y de debilitar las energías de su espíritu y de su cuerpo (242).

Es propio de una universidad católica presentar una estructura orgánica de la doctrina social de la Iglesia (Pontificio Consejo "Justicia y Paz", 2005), con el objetivo de desarrollar en sus estudiantes el espíritu crítico social (I Concilio Plenario, 1537) de tal manera, que ellos crezcan en la conciencia social, que desarrollen competencias que les ayuden a actuar y decidan de acuerdo a la justicia social. Y es aquí donde se le presenta el principal desafío a la universidad católica: dar testimonio de la justicia social. Sin duda alguna, frente al desafío de un mercantilismo antihumano, que inculca en los estudiantes un pensamiento puramente mercantil y mecanizado, se hace cada vez más difícil salir de las sospechas de que las universidades católicas no cumplen con su compromiso social frente a la Iglesia y a la sociedad, ya que en sus aulas no se brinda el espacio para el crecimiento de una conciencia social y más bien fomentan el acomodamiento hacia lo que pide el mercado.

Consciente de esta situación, la PUCMM ha estructurado su currículo con ejes transversales, tanto de manera vertical como horizontal, de tal manera que permita a los estudiantes un acercamiento personal y una reflexión activa sobre la realidad de su contexto social e histórico. Asignaturas tales como: Ética de las Profesiones, Moral Médica, Antropología Cristiana, Matrimonio Sacramento de Amor, La Persona de Jesús, Doctrina Social de la Iglesia, Iglesia en el Mundo Actual, Introducción a la Biblia y Filosofía, más que una simple cátedra se convierten en espacios de discusión seria donde docentes y estudiantes interactúan de manera crítica en la búsqueda de soluciones a las problemáticas actuales.
Junto a las asignaturas, se encuentran las actividades culturales promotoras de la responsabilidad social e identidad con la nación. Del mismo modo, se resalta el trabajo de la pastoral universitaria, la cual involucra a los estudiantes, docentes y personal administrativo en los procesos de reflexión personal, en vista de un compromiso como cristianos. Sin embargo, es notable que aún el currículo de la PUCMM no permite la total integración de todas las actividades al sistema de enseñanzaaprendizaje, pues si bien está estructurado de manera vertical y horizontal, no es abierto y aún tiene que superar las barreras de la inflexibilidad.

No se puede dejar de mencionar que también pertenecen al currículo todas las actividades que la Universidad realiza con otras instituciones educativas, gubernamentales, empresariales ysociales. Granreconocimiento es el aportequebrindalaPUCMM al diálogo nacional, como espacio de entendimiento entre los dominicanos. Además, se resaltan los seminarios, simposios, conferencias y talleres celebrados dentro de la Universidad, en los cuales siempre se ha garantizado una presencia cristiana.

Muchos de los egresados de la PUCMM dan testimonio de su compromiso social, apego a la ética y a los principios cristianos. Esto es ya signo del grado de toma de conciencia que comienza ya en las aulas.

Junto a esto, es notable la identificación del profesorado con los principios que dieron origen a la academia y se observa que muchos de ellos promueven en las aulas el compromiso social. No obstante, existe en la actualidad una gran preocupación por parte de los docentes frente a los estudiantes. Los docentes observan la carencia de juicio crítico frente a los problemas sociales que afectan la sociedad actual. Ellos indican que gran parte de los estudiantes centran su preocupación en la formación

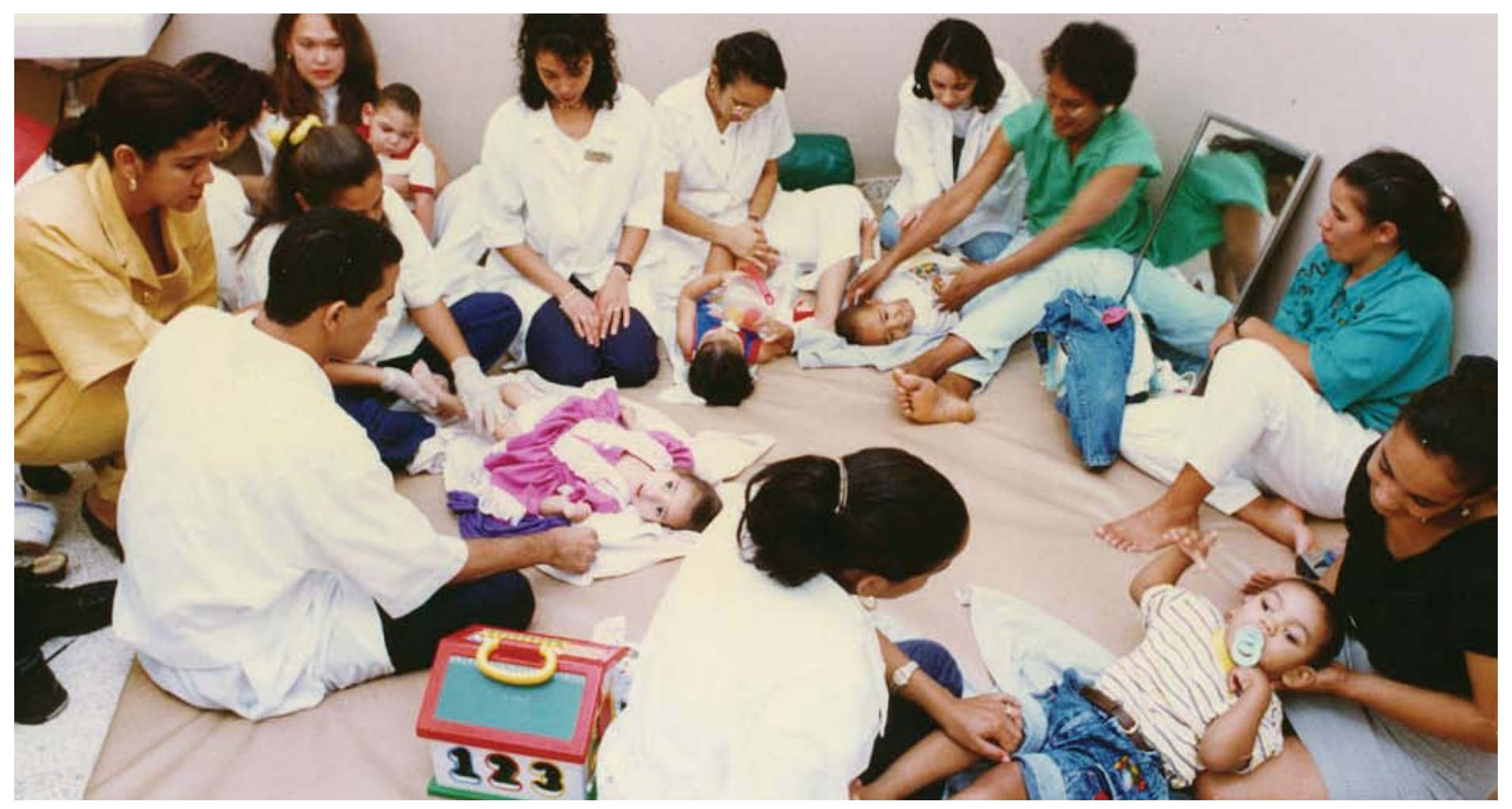


profesional, dejando en segundo plano su formación humana. Sin embargo, cuando ellos experimentan situaciones de conflicto en sus vidas, vuelven su mirada hacia la persona, su crecimiento y su papel a desempeñar en la sociedad. Es aquí donde los espacios de crecimiento, mencionados anteriormente, son de gran ayuda a la formación personal.

Es al final de la Encíclica que el Papa hace referencia al papel educativo de la Iglesia y de su función de maestra, cuando escribe: "Es bien sabido que la Iglesia ha enseñado siempre y, sigue enseñando, que los progresos científicos y técnicos y el consiguiente bienestar material que de ellos se sigue son bienes reales y deben considerase como prueba evidente del progreso de la civilización humana" (246).

El número 246 de la Mater et Magistra ha orientado y seguirá desarrollando la actividad curricular de la PUCMM: "Pero la
Iglesia enseña igualmente que hay que valorar ese progreso de acuerdo con su genuina naturaleza, esto es, como bienes instrumentales puestos al servicio del hombre, para que éste alcance con mayor facilidad su fin supremo, el cual no es otro que facilitar su perfeccionamiento personal, así en el orden natural como en el sobrenatural" (246).

Al número 246 de la Encíclica, le corresponde el artículo 3, párrafo E de los Estatutos de la PUCMM. Ambos hacen girar la mirada del currículo. Se quiere afianzar que la Universidad, dentro de su aporte al desarrollo de la ciencia, no olvide el fin supremo que es la perfección del ser humano. En este sentido, debe formular su currículo de tal manera que ofrezca el mayor espacio posible a la conciliación de la ciencia con el crecimiento integral de la persona humana. Esta es una tarea siempre activa e inconclusa, pues ella orientará el currículo universitario para el logro de los fines que la misma Universidad se plantea.

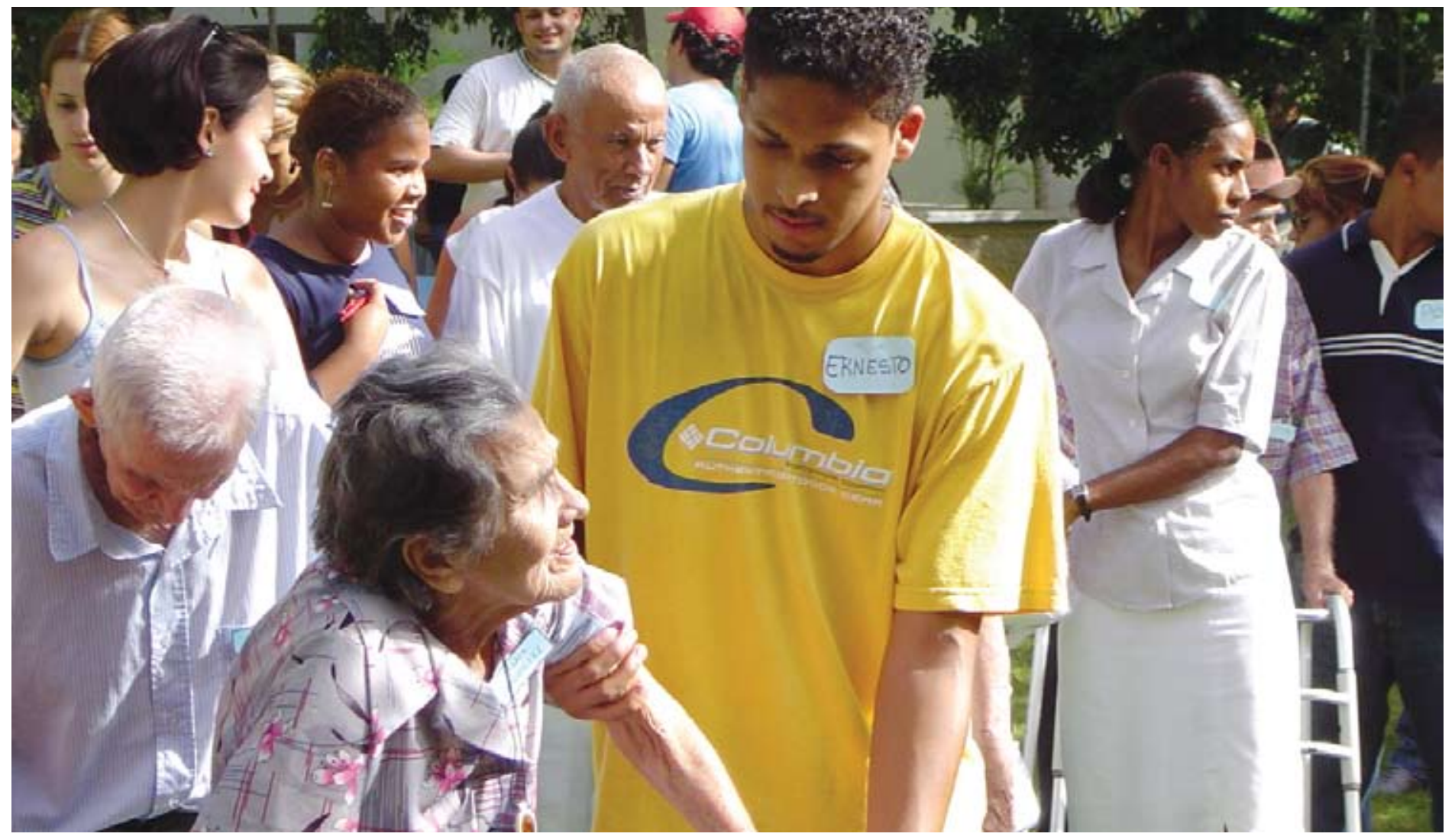

\section{Referencias bibliográficas}

Brugger,W.(2003).Diccionario de filosofía. Barcelona:Herder Conferencia del Episcopado Dominicano. (2000). I Concilio Plenario Dominicano. Santo Domingo: Susaeta.

Flórez Ochoa, R. (2005). Pedagogía del Conocimiento. Bogotá/Buenos Aires: McGraw Hill.

Juan XXIII (1991). Encíclica Mater et Magistra. Bogotá: Paulinas.

Pontificia Universidad Católica Madre y Maestra (1988). Estatutos. Santiago: PUCMM

Pontificio Consejo "Justicia y Paz". (2005). Compendio de la Doctrina Social de la Iglesia. Santo Domingo: Amigo del Hogar.

Sevillano, M. L. (2004). Didáctica en el siglo XXI. Ejes en el aprendizaje y enseñanza de calidad. Madrid/Buenos Aires: McGraw Hill.

Zabalza, M. A. (2004). La enseñanza universitaria. El escenario y sus protagonistas. Madrid: Narcea. 